\title{
Public Awareness about Antibiotic Use and Resistance among Residents in Highland Areas of Vietnam
}

\author{
Thuy Van Ha ${ }^{(D},{ }^{1}$ An Mai Thi Nguyen, ${ }^{2}$ and Ha Song Thi Nguyen ${ }^{3}$ \\ ${ }^{1}$ Department of Health Insurance, Ministry of Health of Vietnam, Hanoi 100000, Vietnam \\ ${ }^{2}$ Department of Planning and Financing, Ministry of Health of Vietnam, Hanoi 100000, Vietnam \\ ${ }^{3}$ Hanoi University of Pharmacy, Hanoi 100000, Vietnam \\ Correspondence should be addressed to Thuy Van Ha; hathuy.moh@gmail.com
}

Received 2 December 2018; Revised 31 March 2019; Accepted 22 April 2019; Published 16 May 2019

Academic Editor: Kumud K. Kafle

Copyright (C) 2019 Thuy Van Ha et al. This is an open access article distributed under the Creative Commons Attribution License, which permits unrestricted use, distribution, and reproduction in any medium, provided the original work is properly cited.

\begin{abstract}
Background. Antibiotic resistance (AR) remains a global crisis. However, the literature on public awareness about antibiotic use and $\mathrm{AR}$ in the highland provinces of Vietnam has been constrained. This study explores the awareness of antibiotic use and resistance among general people in highland provinces in Vietnam and detects associated factors. Methods. A cross-sectional study was performed in five highland provinces with 1000 households. Information about socioeconomic status and awareness regarding prescription medicine use, antibiotic use, and AR was surveyed. Multivariate logistic regression was used to identify associated factors with awareness. Results. $64.2 \%$ of people were aware of prescription drugs. More than two-thirds (67.4\%) of participants were aware of antibiotic use, of whom only $55.8 \%$ were aware of AR. Higher age, education, and family income were positively associated with being aware of prescription medicine, antibiotic, and AR. Females had a lower likelihood of being aware of prescription medicine $(\mathrm{OR}=0.64 ; 95 \% \mathrm{CI}=0.45-0.90)$ compared to male counterparts. Those being freelancers were more likely to be aware of antibiotic resistance $(\mathrm{OR}=2.30 ; 95 \% \mathrm{CI}=1.13-4.67)$ compared to those working in agriculture/fishery/forestry sector. Compared to Kinh ethnic, most ethnic minorities were less likely to be aware of prescription medicine, antibiotic, and AR. Conclusions. This study showed a low awareness regarding prescription medicine, antibiotic use, and AR among public people in the highland provinces of Vietnam. Further systemic and didactic educational interventions targeting females, low education, low income, ethnic minorities, and those working in agriculture/fishery/forestry sector in this setting should be performed and evaluated to improve the awareness about antibiotic use and resistance.
\end{abstract}

\section{Introduction}

Antibiotic resistance (AR) is a condition when bacteria change against antibiotics which are developed to cure the illnesses they cause [1]. It is a global crisis and posed as one of the greatest threats to population health. This problem is driven by many factors such as low quality of antibiotics and improper (under- or over-) use of antibiotics (including selfmedication) [1-3]. Self-medication, which refers to the use of any medical products without a prescription or following unprofessional recommendations in treating any illnesses [4, 5], is particularly leading to the AR. Self-medication practice possibly raises incorrect drug selection, drug resistance, uncontrolled adverse effects or drug reactions, misdiagnosis, and delay in medical care [6-8]. Self-medication is a common phenomenon, and the prevalence varies from $12.7 \%$ to $18 \%$ in Spain $[9,10], 32 \%$ to $45.4 \%$ in China [11, 12], 53\% in Mexico [13], and 75\% in the United Kingdom and Chile [14, 15]. Also, the excessive antibiotic utilization in the agriculture sector causes the pool of AR bacteria in the animals, which are then transferred to the human through consuming food from these animals [16, 17]. It is estimated that, in 2050, there will be more than 10 million deaths and 100 trillion USD lost due to AR if no substantial actions have been made to eliminate this emerging threat [18-20].

As inappropriate antibiotic use is the primary cause of $\mathrm{AR}$, responses to this phenomenon prioritize to promote public awareness about AR [21]. Nonetheless, it is evidenced 
that public awareness about AR is insufficient even in wealthy countries $[22,23]$, and it is more severe in low- and middleincome countries, where antibiotic use without a prescription is prevalent [24-26]. For example, a recent survey conducted by the World Health Organization indicated that most of the respondents in developing countries believed that antibiotics could be used to treat viral infections [21]. Many educational interventions have been conducted worldwide to enhance awareness, knowledge, and practice in antibiotic use; however, the effects were not clear and varied across study settings [27-29]. Thus, further evidence on public awareness about AR in specific settings should be required, which can be used to contextualize and optimize the effectiveness of interventions.

In Vietnam, the inappropriate use of antibiotics and prescription drugs are pervasive, particularly in hospitals. A study in Ho Chi Minh City found that $93 \%$ of patients admitted to the intensive care unit had resisted to at least one antibiotic [30]. Another study showed that about onethird of patients experienced misuse of prescription drugs [31]. Nguyen et al. indicated that $63 \%$ of children in rural areas used unnecessary antibiotics, which most of them were prescribed by health professionals, to treat acute respiratory infections [32]. Moreover, Do et al. found that $88 \%$ and $91 \%$ of antibiotics in urban and rural were sold without a prescription, respectively [33]. However, the literature on public awareness about AR in highland provinces, which had a diversity of ethnicities with different cultural approaches in treating diseases, has been constrained. This study, therefore, aims to explore the awareness of antibiotics use and AR among general people in the highland provinces of Vietnam and detect potential associated factors. This study could be served as a baseline survey for further interventions to promote the proper use of antibiotics in this population.

\section{Materials and Methods}

2.1. Study Designs and Sampling Method. We conducted a cross-sectional survey from July to November 2018 in five highland provinces of Vietnam including Kon Tum, Gia Lai, Dak Lak, Dak Nong, and Lam Dong. A multistage sampling method was employed to recruit participants. First, a list of districts and communes in each province was developed by the local authorities. A total of 721 communes in 62 districts were listed in the sample frame. Then, by using computer software, we randomly selected two districts in each province (10 districts/5 provinces), and after that, two communes per district (20 communes/10 districts). Then, we randomly selected five villages in each commune and ten households per village. Door-to-door recruitment strategy was used to enroll participants until reaching sufficient sample size.

The sample size was calculated by using the formula for estimating a population proportion with specified absolute precision. We expected that the prevalence of residents being aware of AR was 50\%. With a marginal error (absolute precision $)=0.07$ and a confident level $=95 \%$, the total sample size for each province was 196 households. We also added $5 \%$ of sample size for preventing if the household's representative refused to participate or they incompletely answered the interview. A total of 1029 households were randomly selected from the sampling frame. The participants were invited if they were 1 , aged from 18 years or more, and 2, head of households or individuals who were responsible for purchasing medicines for the household.

2.2. Data Collection and Measurements. Face-to-face interviews were performed to collect the data from 15 to 20 minutes. A structured questionnaire was developed for the survey. A pilot survey was conducted with ten households in Dak Lak province. Data of these households were not included in the final dataset. After the pilot, we received the feedbacks from households about the content, language, and logical order of items in the questionnaire. A major revision was performed to ensure the cultural appropriateness of the questionnaire. The final version of questionnaire was produced and approved by the local authorities. A two-day training course was conducted by the principal investigator and the research team who had expertise in antibiotic use and resistance. Interviewers consisted of local health workers who had experiences in working with households. They were informed about the objectives of the survey and the content of the questionnaires, as well as trained necessary interview skills to collect data consistently with high quality.

The questionnaire included information about the socioeconomic status of respondent (age, gender, ethnic, education, marital status, and occupation) and household (number of family members, number of children in the family, number of people having health insurance in the family, and annual household income). People belonging to other ethnics instead of "Kinh" ethnic were classified as "ethnic minorities" since "Kinh" has been the dominant ethnic in Vietnam.

The other parts of the questionnaire were questions about "awareness of prescription drug", "awareness of antibiotic use", and "awareness of antibiotic resistance". In this study, antibiotics are defined as drugs that are used to "prevent and treat bacterial infection" according to the World Health Organization [1]. Our questions were referred from previous studies in the world. Respondents were asked to report whether they were aware of prescription drugs by defining prescription drugs accurately [34]. We also asked patients to respond whether they were aware of antibiotic and AR (including definition of AR) ("Have you ever heard of antibiotics/antibiotic resistance?" - Yes/No; "If you have heard, do you know what antibiotic resistance means?") [35, 36], whether they knew that using antibiotic required prescriptions ("Do you need a prescription when you use antibiotics?" - Yes/No/Don't know) [37], who qualified prescribers were ("If you have to use antibiotics, whose prescription should you follow?") $[35,36]$, solutions when health was not improved after the course of antibiotic ("If your health is not improved after the antibiotic course, what will you do?") [38], and negative effects of antibiotic use ("In your opinion, what are the negative effects of antibiotics use?") $[38,39]$. Details of the questionnaire were informed in the Supplementary File 1.

2.3. Statistical Analysis. Data were analyzed using Stata version 14.0. Descriptive analysis including mean, standard 
deviation, frequency, and the percentage was performed to describe the variables. Two-tailed chi-squared and student $\mathrm{t}$-tests were used to assess the differences in socioeconomic characteristics and awareness between males and females. Multivariate logistic regression was used to identify the factors associated with "Being aware of prescription drugs" and "Being aware of antibiotic", and "Being aware of AR". The independent variables included in the models were socioeconomic status of respondent (age, gender, ethnic, education, marital status, and occupation) and household (number of family members, number of children in the family, number of people having health insurance in the family, and household income quintiles). Stepwise backward selection strategies were applied in combination with regression models, using a p-value of log likelihood test at 0.2 as a threshold for selecting the variables to the reduced models. A p-value of less than 0.05 was treated as statistical significance.

2.4. Ethical Consideration. The study protocol was approved by the Institutional Review Board of the Vietnam Ministry of Health. Participants had the rights to stop the interview or withdraw to the study at any time without any barriers. Written informed consent was obtained if they agreed to participate in the study. They did not receive any incentives or reimbursement for participation. The questions were anonymous, and no personal information was collected during the interview.

\section{Results}

Among 1029 households selected, after excluding households that had incomplete data, information of 1000 households was used for data analysis (response rate 97.2\%). A total of 1000 people in 1000 households participated in the study. The demographic characteristics of respondents are indicated in Table 1.

There were $64.2 \%$ of people being aware of prescription drugs. This rate in males was significantly higher than that in females $(\mathrm{p}<0.05)$. More than two-thirds $(67.4 \%)$ of participants were aware of antibiotics. Most of them understood that using antibiotic required prescriptions (83.5\%), of whom $94.9 \%$ were aware that antibiotics had to be prescribed by physicians at the medical facility. There were $8.0 \%$ concerning drug sellers at the drug store as qualified prescribers. More than half of participants (53.9\%) would reexamine health if antibiotics worked ineffectively, while above one-fifth of people (21.8\%) would replace to other antibiotics. Only $18.8 \%$ knew AR as a negative effect of antibiotic use, and only $55.8 \%$ were aware of AR. Most people being aware of AR knew that AR was where bacteria changed to respond to the use of antibiotic, while only $25.3 \%$ knew the causes of AR. (Table 2)

Higher age, education, and family income were positively associated with being aware of prescription medicine, antibiotics, and AR. Females had a lower likelihood of being aware of prescription medicine ( $\mathrm{OR}=0.64 ; 95 \% \mathrm{CI}=0.45-0.90)$ compared to males. Those being freelancers were more likely to be aware of antibiotic resistance $(\mathrm{OR}=2.30 ; 95 \% \mathrm{CI}=1.13-4.67)$ compared to those working in agriculture/fishery/forestry sector. Compared to Kinh ethnic, most of the ethnic minorities were less likely to be aware of prescription medicine, antibiotic, and AR. People who were Mnong ethnic were more likely to know prescription medicine but less likely to know AR (Table 3).

\section{Discussion}

In this study, the results indicated a lack of awareness about appropriate prescription medicine use and antibiotic use as well as AR among the general population in highland areas of Vietnam. Moreover, by using multivariate regression model, we highlighted the most vulnerable populations to the insufficient awareness of these terms, including females, low age, low education, low income, ethnic minorities, and those working in agriculture/fishery/forestry sector.

In recent years, Vietnam has been a hotspot of AR in the world due to the shortage of legislation and regulations to manage self-medication as well as poor prescription drug and antibiotic use practices [40]. A previous study revealed that $83 \%$ of Escherichia coli found among wastewater samples in Vietnamese hospitals resisted to at least one antibiotic, and $32 \%$ could resist multiple antibiotics [41]. Despite the severity of this phenomenon, our findings revealed a limited awareness of highland people about antibiotic use and AR. For instance, only $64.2 \%$; $67.4 \%$, and $55.8 \%$ were aware of prescription medicine, antibiotic, and $\mathrm{AR}$, respectively. Moreover, the result showed the superficiality in the knowledge of these groups since only one-fourth of individuals knowing AR could define the cause of AR. These proportions in our study were comparable to other countries. A study in Hong Kong found that $91 \%$ adults knew the term "antibiotic resistance" [42], and 59.0\% Malaysians perceived that antibiotic misuse could lead to AR [43]. The results in different studies varied due to the different measures, settings as well as sociocultural-economic backgrounds. Nonetheless, the emerging situation of constrained awareness of population in highland provinces of Vietnam should be underlined; thus, further interventions should be elucidated to improve this issue.

Our study was in line with previous surveys worldwide that age, education, and gender were significant predictors to the awareness of antibiotics use [44-47]. Specifically, lower age, lower education, and females were less likely to be aware of prescription medicine, antibiotics use, and AR. A study in Poland found that people who were young and had lower education were more likely to believe that antibiotics could protect against viral infections [44]. Moreover, younger people had a higher likelihood of self-medication [48]. Notably, we found that those working in the agriculture /fishery/forestry sector had a lower chance of being aware of AR. It should be noted that food animal production is a potential source of AR due to the overuse of antibiotic during farming activities [49].

Meanwhile, the findings demonstrated the susceptibility of ethnic minorities in AR since they were less likely to be aware of antibiotic and AR. Ethnics minorities in Vietnam have been found to have limited health care service and health information access $[50,51]$. Therefore, mandatory 
TABLE 1: Sociodemographic characteristics.

\begin{tabular}{|c|c|c|c|c|c|c|c|}
\hline \multirow{2}{*}{ Characteristics } & \multicolumn{2}{|c|}{ Male } & \multicolumn{2}{|c|}{ Female } & \multicolumn{2}{|c|}{ Total } & \multirow{2}{*}{ p-value } \\
\hline & $\mathrm{n}$ & $\%$ & $\mathrm{n}$ & $\%$ & $\mathrm{n}$ & $\%$ & \\
\hline Total & 421 & 42.1 & 579 & 57.9 & 1000 & 100.0 & \\
\hline \multicolumn{8}{|l|}{ Age group } \\
\hline$\leq 30$ years old & 153 & 36.3 & 238 & 41.1 & 391 & 39.1 & $<0.01$ \\
\hline $31-40$ years old & 165 & 39.2 & 139 & 24 & 304 & 30.4 & \\
\hline $41-50$ years old & 46 & 10.9 & 91 & 15.7 & 137 & 13.7 & \\
\hline $51-60$ years old & 38 & 9 & 75 & 13 & 113 & 11.3 & \\
\hline$>60$ years old & 19 & 4.5 & 36 & 6.2 & 55 & 5.5 & \\
\hline \multicolumn{8}{|l|}{ Occupation } \\
\hline Work in agriculture / fishery / forestry sector & 312 & 74.1 & 452 & 78.1 & 764 & 76.4 & $<0.01$ \\
\hline White-collar worker & 17 & 4 & 24 & 4.1 & 41 & 4.1 & \\
\hline Business & 23 & 5.5 & 32 & 5.5 & 55 & 5.5 & \\
\hline Freelancer & 44 & 10.5 & 9 & 1.6 & 53 & 5.3 & \\
\hline Retirement & 7 & 1.7 & 16 & 2.8 & 23 & 2.3 & \\
\hline Housemaker & 4 & 1 & 41 & 7.1 & 45 & 4.5 & \\
\hline Other & 14 & 3.3 & 5 & 0.9 & 19 & 1.9 & \\
\hline \multicolumn{8}{|l|}{ Education } \\
\hline Illiterate & 28 & 6.7 & 93 & 16.1 & 121 & 12.1 & $<0.01$ \\
\hline Elementary school & 94 & 22.3 & 135 & 23.3 & 229 & 22.9 & \\
\hline Secondary school & 156 & 37.1 & 211 & 36.4 & 367 & 36.7 & \\
\hline High school & 104 & 24.7 & 94 & 16.2 & 198 & 19.8 & \\
\hline Vocational training/College & 19 & 4.5 & 39 & 6.7 & 58 & 5.8 & \\
\hline University/Postgraduate & 20 & 4.8 & 7 & 1.2 & 27 & 2.7 & \\
\hline \multicolumn{8}{|l|}{ Ethnic } \\
\hline Kinh & 239 & 56.8 & 211 & 36.4 & 450 & 45 & $<0.01$ \\
\hline Gia rai & 32 & 7.6 & 92 & 15.9 & 124 & 12.4 & \\
\hline E de & 6 & 1.4 & 38 & 6.6 & 44 & 4.4 & \\
\hline Xo dang & 29 & 6.9 & 42 & 7.3 & 71 & 7.1 & \\
\hline Mnong & 47 & 11.2 & 55 & 9.5 & 102 & 10.2 & \\
\hline Cil & 11 & 2.6 & 50 & 8.6 & 61 & 6.1 & \\
\hline Nung & 17 & 4 & 16 & 2.8 & 33 & 3.3 & \\
\hline Ro ngao & 18 & 4.3 & 47 & 8.1 & 65 & 6.5 & \\
\hline Other & 22 & 5.2 & 28 & 4.8 & 50 & 5 & \\
\hline \multicolumn{8}{|l|}{ Household economic classification } \\
\hline Poor & 66 & 15.7 & 113 & 19.5 & 179 & 17.9 & 0.10 \\
\hline Near-poor & 44 & 10.5 & 75 & 13 & 119 & 11.9 & \\
\hline \multirow[t]{2}{*}{ Non-poor } & 311 & 73.9 & 391 & 67.5 & 702 & 70.2 & \\
\hline & Mean & SD & Mean & SD & Mean & SD & \\
\hline Age & 36.0 & 11.5 & 37.3 & 13.4 & 36.7 & 12.7 & 0.51 \\
\hline Number of members in family & 5.0 & 1.8 & 4.8 & 1.8 & 4.9 & 1.8 & 0.11 \\
\hline Annual household income & 82.8 & 73.3 & 76.1 & 118.8 & 79.0 & 102.1 & $<0.01$ \\
\hline
\end{tabular}

educational training about prescription medicine, antibiotic use, and AR should be reinforced to these populations to ensure sufficient knowledge about these health problems.

This study has several methodological issues that should be acknowledged. First, the causal relationships between the awareness and its associated factors could not be established due to the nature of study design. Second, the self-reported approach might result in recall bias when we asked them to report annual household income and social desirability bias when respondents might give the answers that were viewed favorably by interviewers. However, we have trained the data collection team carefully and developed the data collect guideline to reduce the bias. Third, several critical information was not included in the study, for example, participants' behaviors, impacts of family and social relationships, or health service quality. Moreover, although we conducted the study on a large scale with 1000 households, our generalizability might be limited and not represent to 
TABLE 2: Awareness and practice about safe antibiotic use.

\begin{tabular}{|c|c|c|c|c|c|c|c|}
\hline \multirow{2}{*}{ Characteristics } & \multicolumn{2}{|c|}{ Male } & \multicolumn{2}{|c|}{ Female } & \multicolumn{2}{|c|}{ Total } & \multirow{2}{*}{ p-value } \\
\hline & $\mathrm{n}$ & $\%$ & $\mathrm{n}$ & $\%$ & $\mathrm{n}$ & $\%$ & \\
\hline Being aware of prescription drugs $(n=1000)$ & 307 & 72.9 & 335 & 57.9 & 642 & 64.2 & $<0.01$ \\
\hline Being aware of antibiotic $(n=1000)$ & 306 & 72.7 & 368 & 63.6 & 674 & 67.4 & $<0.01$ \\
\hline Need prescriptions when using antibiotic $(n=674)$ & 266 & 86.9 & 297 & 80.7 & 563 & 83.5 & 0.09 \\
\hline \multicolumn{8}{|l|}{ Prescribers $(n=563)$} \\
\hline Physicians at medical facility & 246 & 92.5 & 288 & 97.0 & 534 & 94.9 & 0.02 \\
\hline Drug sellers at drug store & 25 & 9.4 & 20 & 6.7 & 45 & 8.0 & 0.24 \\
\hline Friends/relatives/neighbourhoods & 0 & 0.0 & 2 & 0.7 & 2 & 0.4 & 0.18 \\
\hline Old prescriptions & 1 & 0.4 & 1 & 0.3 & 2 & 0.4 & 0.94 \\
\hline Other & 3 & 1.1 & 0 & 0.0 & 3 & 0.5 & 0.07 \\
\hline \multicolumn{8}{|l|}{ Solutions when health was not improved after the antibiotic course $(n=674)$} \\
\hline Replace to other antibiotics & 62 & 20.3 & 85 & 23.1 & 147 & 21.8 & 0.38 \\
\hline Increase dose & 7 & 2.3 & 12 & 3.3 & 19 & 2.8 & 0.45 \\
\hline Re-examination & 175 & 57.2 & 188 & 51.2 & 363 & 53.9 & 0.11 \\
\hline Ask advices from drug sellers/physicians & 59 & 19.3 & 121 & 32.9 & 180 & 26.7 & $<0.01$ \\
\hline Ask friends/relatives/neighbourhoods & 0 & 0.0 & 3 & 0.8 & 3 & 0.5 & 0.11 \\
\hline Other & 19 & 6.2 & 15 & 4.1 & 34 & 5.0 & 0.21 \\
\hline Unknown & 25 & 8.2 & 17 & 4.6 & 42 & 6.2 & 0.06 \\
\hline \multicolumn{8}{|l|}{ Negative effects of antibiotic use $(n=674)$} \\
\hline $\mathrm{AR}$ & 51 & 16.7 & 76 & 20.7 & 127 & 18.8 & 0.19 \\
\hline Drug allergy & 86 & 28.1 & 105 & 28.5 & 191 & 28.3 & 0.90 \\
\hline Harm to health & 125 & 40.9 & 151 & 41.0 & 276 & 41.0 & 0.96 \\
\hline Other & 5 & 1.6 & 15 & 4.1 & 20 & 3.0 & 0.06 \\
\hline Unknown & 77 & 25.2 & 92 & 25.0 & 169 & 25.1 & 0.96 \\
\hline Being aware of $A R(n=674)$ & 182 & 59.5 & 194 & 52.7 & 376 & 55.8 & 0.08 \\
\hline \multicolumn{8}{|l|}{ Definition of $A R(n=376)$} \\
\hline Condition that bacteria change to respond the use of antibiotic & 153 & 84.1 & 153 & 78.9 & 306 & 81.4 & 0.20 \\
\hline Occur when using antibiotics without prescriptions, or sufficient dosage or time & 48 & 26.4 & 47 & 24.2 & 95 & 25.3 & 0.63 \\
\hline Other & 5 & 2.8 & 10 & 5.2 & 15 & 4.0 & 0.23 \\
\hline Unknown & 11 & 6.0 & 11 & 5.7 & 22 & 5.9 & 0.88 \\
\hline
\end{tabular}

other settings. Thus, our findings should be used in caution. Further studies should be warranted to fill the knowledge gap in the awareness about prescription medicine use, antibiotic use, and AR among highland residents.

\section{Conclusion}

This study shows a low awareness regarding prescription medicine and antibiotic use among public people in highland provinces in Vietnam. The findings also indicated that females, low education, low income, ethnic minorities, and those working in agriculture/fishery/forestry sector should be the target groups in future interventions in this setting.

\section{Data Availability}

Data in this manuscript belongs to the Vietnam Ministry of Health. Please contact the corresponding author for further request.

\section{Conflicts of Interest}

The authors declare no conflicts of interest.

\section{Authors' Contributions}

Thuy Van Ha, An Mai Thi Nguyen, and Ha Song Thi Nguyen contributed to conceptualization; Thuy Van Ha, An Mai Thi Nguyen, and Ha Song Thi Nguyen were responsible for formal analysis; Thuy Van Ha was responsible for funding acquisition; Thuy Van Ha, An Mai Thi Nguyen, and $\mathrm{Ha}$ Song Thi Nguyen contributed to investigation; Thuy Van $\mathrm{Ha}$ and Ha Song Thi Nguyen contributed to methodology; Thuy Van Ha, An Mai Thi Nguyen, and Ha Song Thi Nguyen contributed to project administration; Thuy Van Ha, An Mai Thi Nguyen, and Ha Song Thi Nguyen wrote the original draft; Thuy Van Ha, An Mai Thi Nguyen, and Ha Song Thi Nguyen are responsible for writing the paper and reviewing and editing. 
TABLE 3: Associated factors with the awareness about safe prescription medicine and antibiotic use.

\begin{tabular}{|c|c|c|c|c|c|c|}
\hline \multirow{2}{*}{ Characteristics } & \multicolumn{2}{|c|}{ Being aware of prescription medicine } & \multicolumn{2}{|c|}{ Being aware of antibiotic } & \multicolumn{2}{|c|}{ Being aware of $\mathrm{AR}$} \\
\hline & OR & $95 \% \mathrm{CI}$ & OR & $95 \% \mathrm{CI}$ & OR & $95 \% \mathrm{CI}$ \\
\hline Age & $1.03 * *$ & $1.02 ; 1.05$ & & & $1.02 *$ & $1.00 ; 1.03$ \\
\hline Education & $2.10 * *$ & $1.74 ; 2.54$ & $2.08 * *$ & $1.76 ; 2.46$ & $2.44 * *$ & $2.02 ; 2.94$ \\
\hline \multicolumn{7}{|l|}{ Gender } \\
\hline Male & ref & & & & & \\
\hline Female & $0.64 *$ & $0.45 ; 0.90$ & & & & \\
\hline \multicolumn{7}{|l|}{ Ethnic } \\
\hline Kinh & ref & & ref & & ref & \\
\hline Gia rai & $0.32 * *$ & $0.18 ; 0.56$ & $0.18 * *$ & $0.10 ; 0.32$ & $0.12 * *$ & $0.05 ; 0.30$ \\
\hline E de & $0.27 * *$ & $0.12 ; 0.60$ & & & $0.32 *$ & $0.13 ; 0.81$ \\
\hline Xo dang & 0.62 & $0.33 ; 1.17$ & $0.41 * *$ & $0.22 ; 0.78$ & $0.22 * *$ & $0.09 ; 0.57$ \\
\hline Mnong & $2.79 * *$ & $1.54 ; 5.05$ & 1.60 & $0.96 ; 2.66$ & $0.50 *$ & $0.27 ; 0.93$ \\
\hline Cil & & & & & 0.65 & $0.34 ; 1.24$ \\
\hline Ro ngao & 0.71 & $0.35 ; 1.43$ & $0.26 * *$ & $0.12 ; 0.56$ & $0.32 *$ & $0.11 ; 0.94$ \\
\hline \multicolumn{7}{|l|}{ Occupation } \\
\hline Work in agriculture/fishery /forestry sector & ref & & ref & & & \\
\hline Freelancer & & & 1.86 & $0.82 ; 4.20$ & $2.30 *$ & $1.13 ; 4.67$ \\
\hline Retirement & 5.60 & $0.69 ; 45.37$ & & & & \\
\hline \multicolumn{7}{|l|}{ Household income quintile } \\
\hline Poorest & ref & & ref & & ref & \\
\hline Middle & $2.00 * *$ & $1.28 ; 3.11$ & $1.62 *$ & $1.07 ; 2.47$ & $1.90 * *$ & $1.17 ; 3.08$ \\
\hline Rich & $2.88 * *$ & $1.74 ; 4.75$ & $2.55 * *$ & $1.62 ; 4.02$ & $2.56 * *$ & $1.59 ; 4.13$ \\
\hline Richest & $4.83 * *$ & $2.59 ; 9.00$ & $4.07 * *$ & $2.38 ; 6.95$ & $4.20 * *$ & $2.48 ; 7.10$ \\
\hline Number of members in family & 0.92 & $0.84 ; 1.01$ & 0.92 & $0.84 ; 1.00$ & & \\
\hline
\end{tabular}

$* * \mathrm{p}<0.01 ; * \mathrm{p}<0.05$

\section{Supplementary Materials}

Supplementary File 1: questionnaire of this study. This questionnaire included information collected in the study. (Supplementary Materials)

\section{References}

[1] "Antibiotic resistance," http://www.who.int/news-room/factsheets/detail/antibiotic-resistance.

[2] T. Mason, C. Trochez, R. Thomas, M. Babar, I. Hesso, and R. Kayyali, "Knowledge and awareness of the general public and perception of pharmacists about antibiotic resistance," BMC Public Health, vol. 18, no. 1, article no 711, 2018.

[3] H. Goossens, M. Ferech, R. Vander Stichele, M. Elseviers, and ESAC Project Group, "Outpatient antibiotic use in Europe and association with resistance: a cross-national database study," The Lancet, vol. 365, no. 9459, pp. 579-587, 2005.

[4] M. Hernández Juyol and J. R. Boj Quesada, "Dentistry and selfmedication: A current challenge," Medicina Oral Patología Oral y Cirugía Bucal, vol. 7, no. 5, pp. 344-347, 2002.

[5] A. Shaghaghi, M. Asadi, and H. Allahverdipour, "Predictors of self-medication behavior: A systematic review," Iranian Journal of Public Health, vol. 43, no. 2, pp. 136-146, 2014.

[6] C. M. Hughes, J. C. McElnay, and G. F. Fleming, "Benefits and risks of self medication,” Drug Safety, vol. 24, no. 14, pp. 10271037, 2001.
[7] A. D. Patil, "Self medication: a potentially avoidable cause of antibiotic misuse and resistance," International Journal of Basic \& Clinical Pharmacology, vol. 2, no. 2, 2017.

[8] D. Bennadi, "Self-medication: a current challenge," Journal of Basic and Clinical Pharmacy, vol. 5, no. 1, pp. 19-23, 2014.

[9] A. F. Guzmán, F. Caamano, and J. J. Gestal-Otero, "Sociodemographic factors related to self-medication in Spain," European Journal of Epidemiology, vol. 16, no. 1, pp. 19-26, 2000.

[10] P. Carrasco-Garrido, R. Jiménez-García, V. H. Barrera, and A. G. de Miguel, "Predictive factors of self-medicated drug use among the Spanish adult population," Pharmacoepidemiology and Drug Safety, vol. 17, no. 2, pp. 193-199, 2008.

[11] X. Lei, H. Jiang, C. Liu, A. Ferrier, and J. Mugavin, "Selfmedication practice and associated factors among residents in Wuhan, China," International Journal of Environmental Research and Public Health, vol. 15, no. 1, p. 68, 2018.

[12] C. L. K. Lam, M. G. Catarivas, C. Munro, and I. J. Lauder, "Self-medication among Hong Kong Chinese," Social Science \& Medicine, vol. 39, no. 12, pp. 1641-1647, 1994.

[13] F. R. Balbuena, A. B. Aranda, and A. Figueras, "Self-medication in older urban Mexicans: an observational, descriptive, crosssectional study," Drugs \& Aging, vol. 26, no. 1, pp. 51-60, 2009.

[14] D. H. James and D. P. French, "The development of the SelfMedicating Scale (SMS): A scale to measure people's beliefs about self-medication," Pharmacy world and science, vol. 30, no. 6, pp. 794-800, 2008.

[15] K. Fuentes Albarrán and L. Villa Zapata, "Analysis and quantification of self-medication patterns of customers in community 
pharmacies in southern Chile," Pharmacy world and science, vol. 30, no. 6, pp. 863-868, 2008.

[16] L. L. Founou, R. C. Founou, and S. Y. Essack, "Antibiotic resistance in the food chain: A developing country-perspective," Frontiers in Microbiology, vol. 7, article no 1881, 2016.

[17] C. Verraes, S. Van Boxstael, E. Van Meervenne et al., "Antimicrobial resistance in the food chain: A review," International Journal of Environmental Research and Public Health, vol. 10, no. 7, pp. 2643-2669, 2013.

[18] J. ON, “Tackling drug-resistant infections globally: final report and recommendations," in Review On Antimicrobial Resistance 2016, 2016.

[19] Organization WHO, Global Action Plan on Antimicrobial Resistance, World Health Organization, Geneva, Switzerland, 2015.

[20] Organization WHO, Global Priority List of Antibiotic-Resistance Bacteria to Guide Research, Discovery, and Development of New Antibiotics, World Health Organization, Geneva, Switzerland, 2017.

[21] Organization WHO, Antibiotic Resistance: Multi-Country Public Awareness Survey, World Health Organization, Geneva, Switzerland, 2015.

[22] R. R. Carter, J. Sun, and R. L. Jump, "A Survey and Analysis of the American Public's Perceptions and Knowledge About Antibiotic Resistance," Open Forum Infectious Diseases, vol. 3, no. 3, Article ID ofwl12, 2016.

[23] L. K. Watkins, G. V. Sanchez, A. P. Albert, R. M. Roberts, and L. A. Hicks, "Knowledge and Attitudes Regarding Antibiotic Use Among Adult Consumers, Adult Hispanic Consumers, and Health Care Providers - United States, 2012-2013," Morbidity and Mortality Weekly Report (MMWR), vol. 64, no. 28, pp. 767770, 2015.

[24] F. Alhomoud, Z. Aljamea, R. Almahasnah, K. Alkhalifah, L. Basalelah, and F. K. Alhomoud, "Self-medication and selfprescription with antibiotics in the Middle East-do they really happen? A systematic review of the prevalence, possible reasons, and outcomes," International Journal of Infectious Diseases, vol. 57, pp. 3-12, 2017.

[25] M. Ocan, E. A. Obuku, F. Bwanga et al., "Household antimicrobial self-medication: A systematic review and meta-analysis of the burden, risk factors and outcomes in developing countries," BMC Public Health, vol. 15, no. 1, article no 742, 2015.

[26] G. Nepal and S. Bhatta, "Self-medication with antibiotics in WHO Southeast Asian region: a systematic review," Cureus, vol. 10, Article ID e2428, 2018.

[27] E. L. A. Cross, R. Tolfree, and R. Kipping, "Systematic review of public-targeted communication interventions to improve antibiotic use," Journal of Antimicrobial Chemotherapy, vol. 72, no. 4, pp. 975-987, 2017.

[28] C. A. M. McNulty, T. Nichols, P. J. Boyle, M. Woodhead, and P. Davey, "The English antibiotic awareness campaigns: did they change the public's knowledge of and attitudes to antibiotic use?" Journal of Antimicrobial Chemotherapy, vol. 65, no. 7, pp. 1526-1533, 2010.

[29] B. Huttner, H. Goossens, T. Verheij, and S. Harbarth, "Characteristics and outcomes of public campaigns aimed at improving the use of antibiotics in outpatients in high-income countries," The Lancet Infectious Diseases, vol. 10, no. 1, pp. 17-31, 2010.

[30] G. M. Tran, T. P. Ho-Le, D. T. Ha et al., "Patterns of antimicrobial resistance in intensive care unit patients: a study in Vietnam," BMC Infectious Diseases, vol. 17, no. 1, article no 429, 2017.
[31] T. A. Thu, M. Rahman, S. Coffin, M. Harun-Or-Rashid, J. Sakamoto, and N. V. Hung, "Antibiotic use in vietnamese hospitals: a multicenter point-prevalence study," American Journal of Infection Control, vol. 40, no. 9, pp. 840-844, 2012.

[32] N. Q. Hoa, N. T. K. Chuc, H. D. Phuc, M. Larsson, B. Eriksson, and C. S. Lundborg, "Unnecessary antibiotic use for mild acute respiratory infections during 28-day follow-up of 823 children under five in rural Vietnam," Transactions of the Royal Society of Tropical Medicine and Hygiene, vol. 105, no. 11, pp. 628-636, 2011.

[33] D. T. T. Nga, N. T. K. Chuc, N. P. Hoa et al., "Antibiotic sales in rural and urban pharmacies in northern Vietnam: An observational study," BMC Pharmacology \& Toxicology, vol. 15, no. $1,2014$.

[34] "Methodology WIWGfDS, Methodology WCCfDS, Services. WCCfDURaCP: Introduction to drug utilization research, Oslo, Norway: World Health Organization; 2003".

[35] M. André, A. Vernby, J. Berg, and C. S. Lundborg, "A survey of public knowledge and awareness related to antibiotic use and resistance in Sweden," Journal of Antimicrobial Chemotherapy, vol. 65, no. 6, pp. 1292-1296, 2010.

[36] S. S. Kim, S. Moon, and E. J. Kim, "Public Knowledge and Attitudes Regarding Antibiotic Use in South Korea," Journal of Korean Academy of Nursing, vol. 41, no. 6, pp. 742-749, 2011.

[37] A. Kotwani, C. Wattal, P. C. Joshi, and K. Holloway, "Knowledge and perceptions on antibiotic use and resistance among high school students and teachers in New Delhi, India: A qualitative study," Indian Journal of Pharmacology, vol. 48, no. 4, pp. 365371, 2016.

[38] K. K. Corbett, R. Gonzales, B. A. Leeman-Castillo, E. Flores, J. Maselli, and K. Kafadar, "Appropriate antibiotic use: Variation in knowledge and awareness by Hispanic ethnicity and language," Preventive Medicine, vol. 40, no. 2, pp. 162-169, 2005.

[39] M. E. El Zowalaty, T. Belkina, S. A. Bahashwan et al., "Knowledge, awareness, and attitudes toward antibiotic use and antimicrobial resistance among Saudi population," International Journal of Clinical Pharmacy, vol. 38, no. 5, pp. 1261-1268, 2016.

[40] K. V. Nguyen, N. T. Thi Do, A. Chandna et al., "Antibiotic use and resistance in emerging economies: A situation analysis for Viet Nam," BMC Public Health, vol. 13, no. 1, article no 1158, 2013.

[41] L. T. Q. Lien, P. T. Lan, N. T. K. Chuc et al., "Antibiotic resistance and antibiotic resistance genes in Escherichia coli isolates from hospital wastewater in Vietnam," International Journal of Environmental Research and Public Health, vol. 14, no. 7, 2017.

[42] Y. T. Wun, T. P. Lam, K. F. Lam, and K. S. Sun, "Antibiotic use: do parents act differently for their children?" International Journal of Clinical Practice, vol. 66, no. 12, pp. 1197-1203, 2012.

[43] A. L. Oh, M. A. Hassali, M. S. Al-Haddad, S. A. S. Sulaiman, A. A. Shafie, and A. Awaisu, "Public knowledge and attitudes towards antibiotic usage: A cross-sectional study among the general public in the state of Penang, Malaysia," The Journal of Infection in Developing Countries, vol. 5, no. 5, pp. 338-347, 2011.

[44] B. Mazińska, I. Struzycka, and W. Hryniewicz, "Surveys of public knowledge and attitudes with regard to antibiotics in poland: did the european antibiotic awareness day campaigns change attitudes?" Plos One, vol. 12, no. 2, Article ID e0172146, 2017.

[45] J. Vanden Eng, R. Marcus, J. L. Hadler et al., "Consumer attitudes and use of antibiotics," Emerging Infectious Diseases, vol. 9, no. 9, pp. 1128-1135, 2003. 
[46] J. H. S. You, B. Yau, K. C. Choi, C. T. S. Chau, Q. R. Huang, and S. S. Lee, "Public knowledge, attitudes and behavior on antibiotic use: A telephone survey in Hong Kong," Infection, vol. 36, no. 2, pp. 153-157, 2008.

[47] M. Vallin, M. Polyzoi, G. Marrone, S. Rosales-Klintz, K. T. Wisell, and C. S. Lundborg, "Knowledge and attitudes towards antibiotic use and resistance - A latent class analysis of a Swedish population-based sample," Plos One, vol. 11, no. 4, Article ID e0152160, 2016.

[48] L. Grigoryan, F. M. Haaijer-Ruskamp, J. G. M. Burgerhof et al., "Self-medication with antimicrobial drugs in Europe," Emerging Infectious Diseases, vol. 12, no. 3, pp. 452-459, 2006.

[49] A. G. Mathew, R. Cissell, and S. Liamthong, "Antibiotic resistance in bacteria associated with food animals: a United States perspective of livestock production," Foodborne Pathogens and Disease, vol. 4, no. 2, pp. 115-133, 2007.

[50] B. X. Tran, L. H. Nguyen, V. M. Nong, and C. T. Nguyen, "Health status and health service utilization in remote and mountainous areas in Vietnam," Health and Quality of Life Outcomes, vol. 14, no. 1, article no 85, 2016.

[51] N. Toan, L. Trong, B. Höjer, and L. Persson, "Public health services use in a mountainous area, Vietnam: implications for health policy," Scandinavian Journal of Public Health, vol. 30, no. 2, pp. 86-93, 2016. 


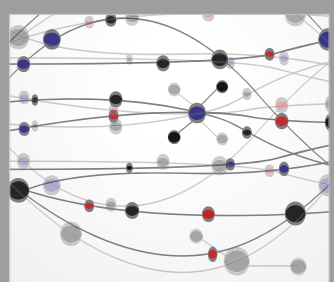

The Scientific World Journal
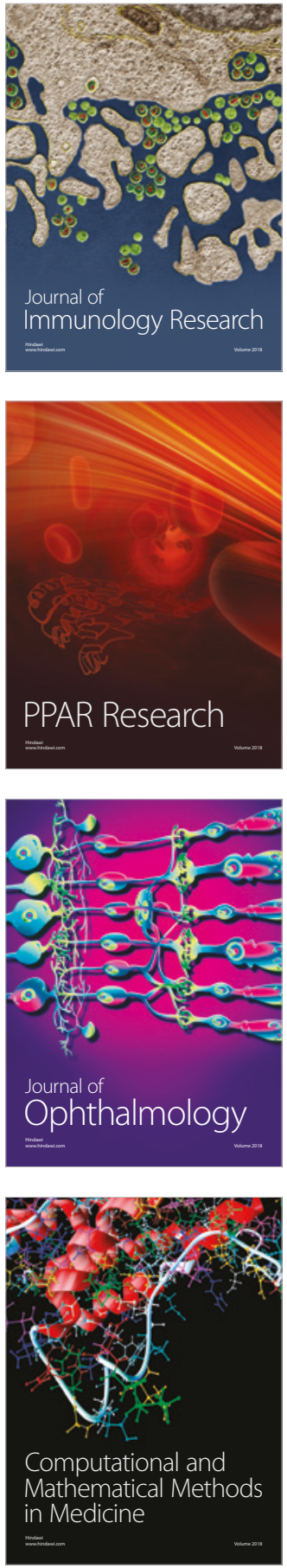

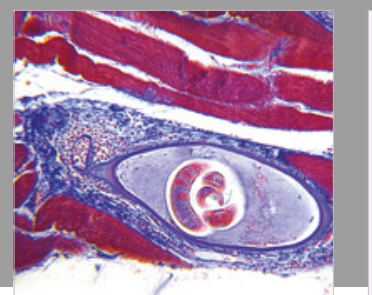

Gastroenterology Research and Practice

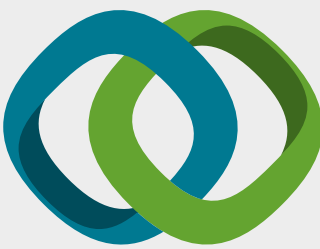

\section{Hindawi}

Submit your manuscripts at

www.hindawi.com
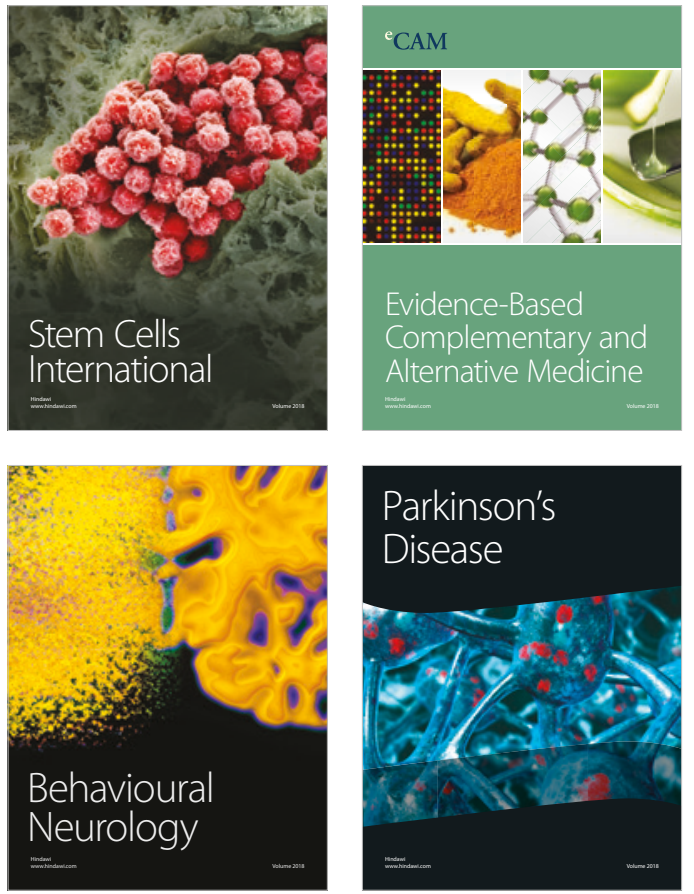

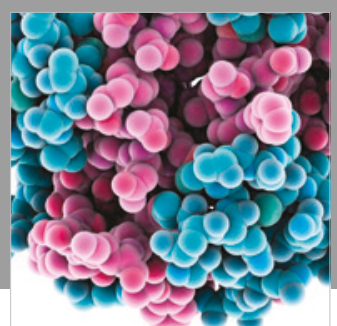

ournal of

Diabetes Research

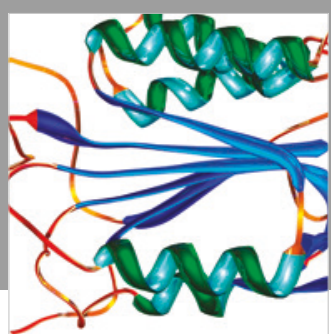

Disease Markers
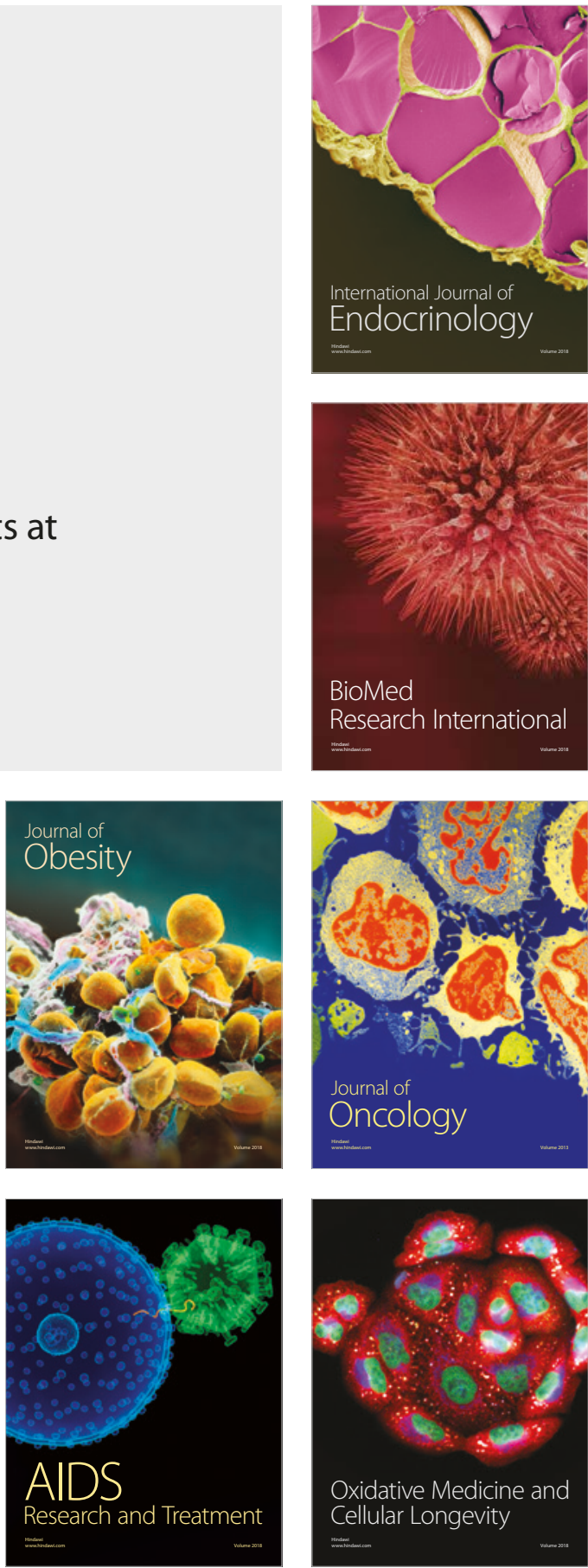